Imaginary Worlds:

\title{
Using Visual Network Scales to Capture Perceptions of Social Networks
}

\author{
Ajay Mehra \\ Steve Borgatti \\ Scott Soltis \\ Theresa Floyd \\ Brandon Ofem \\ Daniel Halgin \\ Virginie Kidwell \\ LINKS Center for Social Network Analysis \\ Department of Management \\ University of Kentucky \\ Email for corresponding author: ajay.mehra@uky.edu
}

To Cite: Mehra, A., Borgatti, S. P., Soltis, S., Floyd, T., Ofem, B., Halgin, D. S., \& Kidwell V. L. (forthcoming). Imaginary worlds: Using visual network scales to capture perceptions of social networks. In D.J. Brass, G. Labianca, A. Mehra, D.S. Halgin, \& S.P. Borgatti (Eds.), Research in the Sociology of Organizations. Vol. 40. Emerald Publishing: Bradford, UK.

Please contact Ajay Mehra (ajaymehra1@gmail.com) or Steve Borgatti (sborgatti@uky.edu) for highresolution images of the visual scales described in this chapter. These network visual scales are available free of charge for academic/research purposes. Those wishing to use the scales for consulting or training must contact us, the copyright holders, for permission prior to use. 


\begin{abstract}
Social networks are not just patterns of interaction and sentiment in the real world; they are also cognitive (re) constructions of social relations, some real, some imagined. Focusing on networks as mental entities, our essay describes a new method that relies on stylized network images to gather quantitative data on how people "see" specific aspects of their social worlds. We discuss the logic of our approach, present several examples of "visual network scales," discuss some preliminary findings, and identify some of the problems and prospects in this nascent line of work on the phenomenology of social networks.
\end{abstract}


Imaginary Worlds: Using Visual Network Scales to Capture Perceptions of Social Networks

Social networks lead a double life. They are, on the one hand, recurring and relatively stable patterns of interaction and sentiment connecting individuals to each other. The study of social networks in this realist guise is well established and easily makes up the bulk of network research. On the other hand, social networks are also phenomenal constructs. In this cognitive guise, they are mental (re)constructions of social relations, some real, some imagined. Now it is true that, as a matter of practice, researchers often learn about interaction and sentiment patterns by asking respondents to tell them about their relations with others. If people are poor at recalling the interpersonal ties around them (e.g., Bernard, Killworth, and Sailer, 1984), then this may call into question the use of subjective report as a basis of collecting data about networks in the real world. Or it could be that the biases of perception and recall that creep into people's reports of the networks around them are systematic and predictable, suggesting that subjective reports of social networks, corrected for these biases, can still be useful for researchers trying to learn about networks as concrete patterns in the world (Freeman and Romney, 1986; cf. Krackhardt, 2014, McEvily, 2014). But there is more that follows from recognizing the dual nature of social networks. First, we can develop and test theories about the antecedents and consequences of the accuracy with which the structure of social networks are cognitively represented in human minds. For example, one study of 36 members of a high-tech company showed that, controlling for formal and informal bases of power the accuracy with which an individual perceived the informal network was positively correlated with individual power in the organization (Krackhardt, 1990). And a different multi-sample study theorized and found that the accuracy with which individuals perceive social ties in workplace networks is a function of 
the social distance between the perceiver and the tie being perceived (Krackhardt \& Kilduff, 1999).

An alternative approach is to focus directly on social networks as mental creations, "apart from any relation they may have to behavior" (Krackhardt, 1987: 110). Such an approach would seek to explore and explain the structure of the social networks that exist in the mind, imaginary worlds that people create and then endeavor to live in. This cognitive approach might strike some as regressive, a retreat back into the mind from the (inter-subjective) concreteness that some see as a distinguishing characteristic of the network approach to the study of social structure (e.g., Mayhew, 1980; Wellman, 1988: 3). But there is rich precedent both classic (e.g., Heider, 1958) and contemporary (see the review in Kilduff and Krackhardt, 2008) to suggest the fruitfulness of such a stance. Which brings us to the question: Why are social networks less studied in their cognitive incarnation? There may be more than one answer to this question, but one is surely that the collection of quantifiable data on individuals' perceptions of social networks can be, to put it mildly, "a formidable task" (Krackhardt, 1987: 114). Indeed, the method that is considered the gold-standard for collecting cognitive social network data-i.e., the cognitive social structures (CSS) approach pioneered by Krackhardt (1987)—is extremely taxing on respondents because it requires each person to report on her perceptions of every possible pair in the sample.

The purpose of this brief essay is to introduce a method that makes it feasible to efficiently collect readily quantifiable data about individuals' perceptions of their social worlds. Two insights prompted us to initiate the development of this method. First, we know that pictorial representations of relationships help researchers make sense of complex social network data (Freeman, 2000). Indeed, the use of graphic imagery to represent relational information was key to the birth of sociometry (Moreno, 1953) and is a core feature of contemporary network analysis 
(Freeman, 2004). And yet we rarely use network visuals to collect data from respondents (cf. Hogan, Carrasco, and Wellman, 2007). Second, we were interested in developing an approach that would allow us to ask respondents directly about the particular network characteristic that a researcher is interested in rather than soliciting responses at the level of dyadic ties and then inferring the network characteristic of interest. For example, Robert may, when prompted, report that he is connected with $\mathrm{A}, \mathrm{B}$, and $\mathrm{C}$ and that there are no ties between $\mathrm{A}, \mathrm{B}$, and $\mathrm{C}$. A researcher could infer from this information that Robert perceives himself to be a structural bridge connecting A, B, and C. However, it could be the case that, despite perceiving the set of dyadic ties connecting himself to A, B, and C, Robert may have never recognized that he is a bridge between the others in the network. Similarly, a respondent could provide tie-level information that indicates that he sees ties between most people in his group and yet he may never come to the realization that his is a densely connected group. Seeing the trees (i.e., ties) does not mean that one sees the forest (i.e., larger network configurations, such as bridging positions). Evidence from psychology suggests that attention is selective; people do not record individual stimuli, they record underlying patterns (Neisser, 1976). Rather than asking about trees and then inferring which features of the forest the respondent sees, our approach would ask respondents directly about the forest they see (or fail to see).

Although we have been developing, refining, and testing this pictorially based method for collecting network perceptions for a couple of years, this line of work is very much in its infancy. We describe below the basic logic and share several examples of our nascent approach, initiate a discussion of its advantages and disadvantages as a method for learning about people's network perceptions, note some preliminary findings from empirical studies we have underway, 
take stock of opportunities and challenges, and invite readers to join us in the work that lies ahead.

\section{Picturing Network Perceptions}

The idea that perceived interpersonal relations can differ from real ones and that this difference can be seen not as error in need of mitigation but as a substantive phenomenon to be theorized and investigated can be traced to Heider (1958; cf. Sartre, 1936). Recognizing the active, constructive role played by perception in helping us cognize the world around us, Heider's phenomenal theory focused on the "nature of the contact between the person and his environment as directly experienced by the person" (1958: 22). Heider was interested in understanding not just how the person sees the people in her social environment but also how the person is directed towards seeing how the people in her social environment, as perceivers themselves, see others. Although there are parallels between how people perceive relations among objects and how people perceive relations among people, Heider recognized that the sentiments and attitudes that people hold towards others are psychological entities, "mentalistic concepts" that cannot be "weighed by a scale, nor examined by a light meter" (1958:32). Even if one focuses exclusively on the perception of interpersonal behaviors, social relationships have to be inferred from some observed sequence of acts. To perceive a relationship between two people requires that one "abstract from... varying modes of behavior an invariant relational aspect" (Nadel, 1958: 10).

Krackhardt's (1987) Cognitive Social Structure method builds directly on these phenomenological insights. Whereas the standard sociometric approach has defined network structure in terms of a set of $\mathrm{R}$ matrices (one matrix for each relation) of the form $R i j$, where $R$ is 
the relation on which the structure is defined, " $i$ " is the "sender" of the relation, and " $j$ " is the receiver of the relation, CSS represents network structure in the form $R i, j, k$ where " $i$ " is the "sender" of the relation, " $j$ " is the receiver, and " $k$ " is the "perceiver." Thus, if the relation $\mathrm{R}$ were friendship, then $\mathrm{R} 1,4,9$ would mean that person 9 thinks that person 1 sees person 4 as a friend. This means that if there were $\mathrm{N}$ actors in a system, then the CSS representation of the system would require $\mathrm{NxNxN}$ matricies. This cognitively oriented approach has advantages over the standard approach for representing network data but a disadvantage is that the amount of information that respondents have to provide is so extensive and time-consuming as to make it "virtually impossible" to study networks made up of more than about 50 people (Krackhardt, 1987: 114).

The visual network scales (VNS) approach also seeks to uncover the perceived social world that respondents see. It does so, however, not by going through the laborious procedure of asking people to report on the relations between every possible pair of people in a system but by presenting respondents with stylized depictions of social network structures and asking them to judge, using a numeric scale, the extent to which their perceptions of the structure of the social world match the stylized network.

Our approach builds on previous work on the use of visual scales in social science research, which recognize the ability of the human mind to make sense of complex information when it is presented as a picture (see Freeman, 2000). The translation of data into images can allow people to readily grasp patterns and anomalies in complex relational data, perhaps because visual data allows humans to use the right hemisphere of the brain (which handles visual imagery) in addition to the left hemisphere (which handles analysis). In the 1700s, William Playfair, a Scottish engineer, created the bar chart, pie chart, and the line graph, visual innovations that 
enabled people to detect patterns they would be unlikely to spot by staring at long lists of numbers (Economist, 2013: 77). Einstein famously struck upon his theory of special relativity in the form of an image (he imagined the world from the perspective of someone travelling on a beam of light) not an equation (Podolny, 2003: 169). Perhaps the most widely used image choice scale in the social sciences is the faces scale, first developed by Kunin (1955; for work on the reliability and validity of the scale, see, e.g., Garra et al., 2010) to assess workplace attitudes. The faces scale presents respondents with a series of images of faces drawn to express emotion along a continuum from extremely positive to extremely negative. The respondent chooses the image that best represents his or her current feeling, sensation or attitude. Kunin originally developed the faces scale to solve an issue of distortion he perceived when complex feelings had to be translated into words. He claimed that the use of facial visuals provided a more accurate measurement of attitudes that were otherwise too complex for respondents to summarize and assess. This very idea — that the human mind can readily use pictures to make sense of otherwise complex relational data - is, of course, what led Moreno, arguably the father of sociometry, to develop the sociogram in the first place, which he saw not merely as a method of visual representation but also as a method of exploration (Moreno, 1953: 95-96). Building on Moreno's insight, we have developed a number of picture-based scales to learn about how respondents perceive/imagine their social worlds. In developing these visual network scales, we have tried be mindful of the fact that although network visualization is a powerful tool for making sense of complex data, it can be easily misused — poorly laid out network diagrams convey little information and can lead to errors in the interpretation of networks (McGrath, Blythe, and Krackhard, 1997). 


\section{Visual Network Scales}

Before presenting respondents with our stylized visual network scales, we first introduce them (Figure 1) to the general idea that social networks can be depicted in two-dimensions using nodes to represent people and lines to represent some relation (e.g., close friendship) that we happen to be interested in. In creating the stylized depictions of various structural configurations, we were mindful of three criteria - correspondence between point distance and path distance; avoidance of placement of nodes in such proximity that they obscure one another; and a preference for equal-length ties - that one could use to optimize the physical layout of the diagrams (see Borgatti, Everett, and Johnson, 2013: 104-106). In addition to producing readable and aesthetically pleasing renderings, our goal was to create diagrams that emphasized only one feature of the network at a time. So, for example, when creating a network diagram to capture respondents' perceptions of 2-step network reach (see below), we chose instantiations of the graph, at each level of the scale, that excluded ties among friends of friends — otherwise, it would be less clear whether we were asking about the extent to which friends have many friends or the extent to which friends' friends tend to be themselves interconnected. Extensive pretesting with network experts and, separately, subjects who had no prior exposure to network theory or network visualization suggested the scales had high face-validity. The feedback from these individuals helped us refine our network images (and the text-based instructions that accompany them) and shore up their content validity.

Ego-Network Structure. The first set of visual network scales we developed focused on an individual's perceptions of her "ego network," which consists of the individual's direct relations and the relations among those to whom she is directly related. We begin by sensitizing (figure 2) 
the respondent to the idea of their "personal network" (respondents, unsurprisingly, did not like the technical label "ego network"). We next asked respondents to indicate, using a Likert-scale, the density of their ego network (Figure 3), the extent to which they perceived themselves as occupying a bridging position in their ego network (Figure 4), and the extent to which their friends themselves had many friends (Figure 5).

Whole-Network Structure. To learn how a respondent perceived the structure of her overall or "whole" social network, we modified the wording of the question about ego network structure so that the question now asked individuals about their perceptions of the structure of relations within the organization as a whole. This allowed us to use the stylized network images to learn how the respondent perceived the density of the whole network (Figure 6), and whether the respondent perceived the structure of the overall network of the organization as best resembling one structured in terms of (a) a core-periphery structure; (b) a clique structure; (c) a sparse network; or (d) a densely connected network (Figure 7).

Perception of Network Change. How social networks change and why is a longstanding and central concern in network theory and research. How people perceive changes in social networks and why has received comparatively little attention. We believe that visual network scales can play a role in advancing our understanding of the perception of network change by providing a picture-based tool for directing respondents' attention to the specific network characteristics changes in which are the object of interest. Figure 8 depicts a visual scale designed to capture respondents' perceptions of changes in the density of their ego-network and figure 9 depicts a visual scale designed to capture respondents' perceptions of changes in the degree to which they 
occupy bridging positions in their ego networks. Figure 10 shows a visual scale that attempts to capture respondents' perceptions of changes in their relative centrality in the overall network over time.

Retrospective and Prospective Trajectories. Human beings are imaginative creatures oriented towards the past and the future even as they negotiate the present (Emirbayer and Mische, 1998). People like to tell stories about how their various relationships have waxed and waned over time and they construct imaginative narratives about the course their relationships might follow in the future. How we act in a current relationship may be conditioned both by how we see its past and how we envision its future. Alfred Schutz, a sociologist who was keenly attuned to this sadly neglected aspect of human agency, sought to understand action from the perspective of the actor temporally embedded in the stream of experience. Life — and perhaps social life in particular — is only rendered sensible, he argued, in retrospect (1967: 47; cf. Schutz,1978). There is promising new work in social psychology on how people think about their relationships over time (e.g., Karney and Frye, 2002), but network research has tended to engage in what Granovetter (1992) has called "temporal reductionism...treating relations and structures of relations as if they had no history that shapes the present situation. In ongoing social relations, human beings do not start fresh each day, but carry the baggage of previous interactions into each new one" (p.34). And just as human action is oriented towards the past, so it is oriented towards the future: "immersed in a temporal flow, they [humans] move "beyond themselves" into the future and construct changing images of where they think they are going" (Emirbayer and Mische, 1998: 984). To make sense of the social maneuverings of people building and breaking ties in the present it may therefore be valuable to account for how people imagine their social worlds unfolding in the future. 
One way to efficiently capture how people retrospect and prospect about their interpersonal ties is to present them with stylized image-based trajectories that relationships commonly take (cf. Flora and Segrin, 2000) and then ask them how they perceive relationships with specific others in retrospect (Figure 11) and prospect (Figure 12). The arc of a human relationship can, of course, be charted along many dimensions. We focused here on the fundamental dimension of tie-valence (like/positive versus dislike/negative). Unlike the other visual network scales we have discussed, this one is focused at the level of specific dyadic ties rather than at the level of the ego network or the whole network. Extending our approach to these alternate levels of analysis should be relatively straightforward.

Network Preferences. When we observe that an individual has a sparse network, we cannot infer that the individual prefers sparse networks. The kind of agency at work in the construction and development of social networks is rarely unbounded. A person could have a preference for living in a densely connected world and yet end up with a sparsely connected network for myriad reasons not least of which is that the others who make up the network have their own preferences for structuring social worlds. One approach to understanding the social structures people prefer to inhabit is to present them with stylized networks and ask them for their preferences (Figures 13-15). A related approach is to present respondents with stylized network diagrams and ask them how they have attempted to transform (or not) such situations in the past (Figure 16).

\section{Preliminary Investigations}

Empirical research using visual network scales is in an early stage but results are starting to trickle in from five separate studies - one of a college sorority, another of a co-ed college fraternity, two lab studies, and a study of a small manufacturing company. Preliminary results 
from the sorority and the fraternity were reported in (Mehra, Borgatti, Soltis, Kidwell, and Floyd, 2010). The data from the two lab studies have neither been presented nor published. Initial results from the small manufacturing plant can be found in Soltis and Floyd (2013). Because the results of these studies are unpublished and have not yet undergone peer review, they should be treated with caution.

Perceptions of social networks do not have to match reality. However, at this early stage it may be interesting to ask how network perceptions measured using visual network scales correspond with traditional measures of network reality. Evidence from the college sorority indicated that our measures of perceived network density, bridging, and 2-step reach were each significantly and positively (but modestly) correlated with measures of density, bridging, and 2-step reach based on sociometric data that were used to code ties as real if both parties agreed that the tie existed (correlations ranged between .24 and .30 , p values for all correlations were less than .01). These correlations were in the same direction in the data from the college fraternity, but only some of the correlations were significant (i.e., perceived density and density were correlated at $.22, \mathrm{p}<.01)$. Using data from the only sample that included both visual network scale data and CSS data, we found that our measure of perceived bridging was positively and significantly correlated $(\mathrm{r}=.40, \mathrm{p}<.05)$ with a measure of bridging (betweenness centrality-Freeman, 1979) but our picture-based measures of perceived density and 2-step reach were not significantly correlated with measures of density and 2-step reach using the CSS data. It is important to keep in mind that CSS and the visual scales may not capture the same cognitions. As we have noted, whereas CSS asks questions at the level of dyads (trees) and infers the structural characteristics of interest (the forest), the visual network scales approach asks directly about the structural characteristic of interest. 
Do our measures of network perception predict outcomes that we would expect them to predict on the basis of theory? Because our measures tap network perceptions, we expected they would be especially likely to predict subjective, personal outcomes. This is what we have found in the data from the college sorority and fraternity. In both samples, the visual scale based measures of ego network characteristics were significant predictors of satisfaction with the organization and a measure of how valuable respondents believed their social networks were for career success and professional development (Mehra et al., 2010). These results controlled for "real" ego network characteristics based on traditional sociometric data, which treated a tie as real if both parties agreed that the tie existed. The satisfaction people felt appeared to be less a function of things (real social networks) than their thoughts of things (network perceptions).

It makes sense that how people perceived the networks around them influenced how satisfied they felt. But did network perceptions, measured using visual network scales, predict how others evaluated a person? The answer is "yes." We found that characteristics of ego networks captured using visual network scales significantly predicted the number of leadership nominations individuals received from others in both the sorority and the fraternity (Mehra et al., 2010). Similarly, the visual network measure of perceived bridging, controlling for the non-significant effects of a measure of bridging based on CSS data, was a significant predictor of the extent to which others evaluated the person's job performance positively (Soltis and Floyd, 2013). Analysis of the data from the two lab studies is ongoing. However, preliminary analysis showed some support for the construct and predictive validity of our scales. In particular, we found that self-monitoring, a measure of personality that reflects an individual's motivation and ability to engage in impression management, was positively related $(\mathrm{p}=.22, \mathrm{p}<.01)$ to our visual scale measuring respondents' preference for occupying bridging positions in their personal networks, a 
result that fits prior evidence from the field (e.g., Sasovova, Mehra, Borgatti, and Schippers, 2010). Preliminary evidence also suggests that extraverts tend to be less likely than introverts to see their relationships as "cooling off" over time $(r=-.26, p<.01)$. Taken together, the results across these studies indicate initial support for the idea that visual network scales tap peoples' perceptions of their social networks and they show reasonable predictive validity. They also suggest that our measures and measures based on the CSS approach while modestly related appear to be, as expected, capturing different aspects of how people perceive their social networks.

\section{Summary and Conclusion}

Social networks exist both as interactional patterns in the real world and as cognitive maps in our heads. Yet the vast majority of network research has focused on networks in their realist guise rather than on networks in their cognitive guise. One reason for this state of affairs may be that tools for systematically studying how people see their social networks are limited and cumbersome. The current gold standard for assessing network perceptions (Krackhardt's Cognitive Social Structures method), for example, poses such heavy burdens on respondents that it is infeasible to collect data about perceptions of even modestly sized networks (Krackhardt, 1987). Moreover, the CSS approach asks individuals to report their perceptions at the level of individual ties and then infers from the data what people see in terms of the underlying structural configurations one can detect in the data. Although this procedure has strengths, one potential disadvantage is that it is unclear whether people really perceive the structural configurations of interest. We have introduced in this paper an alternative approach to gathering network perceptions, one that leverages the ability of humans to understand complex relational data using pictures. Visual network scales offer a way to study not just how people see their present social 
networks but how they perceive their networks over time, in retrospect and in prospect. To the extent that people are the authors of their own histories, people can reinterpret past social relationships and thereby influence their current emotions and attitudes. Similarly, how people envision their social networks unfolding in the future can influence how they react to their current circumstances. It may be that one reason that many individuals seem not to capitalize on the full potential of their social networks is that they are too focused on the trees to see the forest. Visual network scales could be adapted for use as a consciousness-raising and training tool to help individuals to spot, leverage, and create social capital. We also note that in designing the visual network scales discussed in this essay we have largely restricted our focus to aspects of network structure. But our general approach can be used to design visual network scales that cover other important aspects of social networks, such as nodal attributes, tie strength, and tie directionality.

We have summarized in this brief essay preliminary results from a handful of ongoing studies that together suggest that visual network scales may offer a promising approach to understanding the phenomenology of network perception. But there is clearly much work that remains to be done before this promise can be more fully realized. Perhaps the most obvious challenge involves getting a better handle on how the peculiarities of the method/instrument used for capturing network perceptions shapes what respondents tell us about the social networks in their minds. There is probably no perfectly neutral method for learning about social networks as mental constructs. Visual network scales allow researchers to ask respondents directly about specific network configurations (e.g., bridging, reach). However, it may be that people do not think about their networks in terms of such configurations - or at least they do not do so until researchers ask them to. Perhaps people find it more natural to think about their social networks 
at the level of specific trees (dyads) rather than at the level of the forest (broader network configuration). We need to better understand the reactivity of visual network scales and how these relate to the reactivity of alternative approaches to the collection of network perceptions. The approach a researcher should use to gather data on network perceptions in any given study surely depends upon the hypothesis at hand. Nonetheless, we suspect it will be a useful strategy to find ways of combining multiple methods (across studies even if not in the same study) rather than relying exclusively on any one single approach to understanding network cognition.

Human beings are map-makers (Turchi, 2004). We make maps not just of the physical world but also of our social worlds. The maps we construct may at times be horribly skewed and the worlds we envision largely imaginary. Nonetheless, we live in the worlds our maps create. To take this point seriously is not to dissolve the social world but to make it more directly accessible to us. 


\section{ACKNOWLEDGMENTS}

We thank Filip Agneessens, Dan Brass, Travis Grosser, Martin Kilduff, David Krackhardt, Joe Labianca, Zuzana Sasovova, Patrizia Vecchi, Michael Wise, and Meredith Woehler for their comments and criticisms. 


\section{REFERENCES}

Bernard, H.R., Killworth, P., \& Sailer, L. 1984. The problem of informant accuracy: the validity of retrospective data. Annual Review of Anthropology, 13: 495-517.

Borgatti, SB, Everett, MG \& Johnson, JC. 2013. Analyzing social networks. Sage Publications UK.

Emirbayer, M., \& Mische, A. 1998. What is agency? American Journal of Sociology, 103: 9621023.

Flora, J., \& Segrin, C. 2000. Relationship development in dating couples: Implications for relational satisfaction and loneliness. Journal of Social and Personal Relationships, 17: 811-825.

Freeman, L.C. 2000. Visualizing social networks. Journal of Social Structure, 1.

Freeman, L.C. 2004. The development of social network analysis, Empirical Press: Vancouver, British Columbia.

Freeman, L.C. \& Romney, K.A. 1986. Words, deeds, and social structures. Human Organization.

Heider, F. 1958. The psychology of interpersonal relations, Lawrence Erlbaum Associates: Hillsdale, NJ.

Hogan, B., Carrasco, J.A., \& Wellman, B. 2007. Visualizing personal networks: working with participant-aided sociograms. Field Methods, 19: 116-144. 
Garra, G., Singer, A.J., Taira, B.R., Chohan, J., Cardoz, H., Chisena, E., \& Thode, H.C. 2010. Validation of the Wong-Baker FACES Pain Rating Scale in pediatric emergency department patients. Academic Emergency Medicine, 17: 50-54.

Granovetter, M. 1992. Problems of explanation in economic sociology. In N. Nohria and R.J. Eccles (eds.), Networks and Organizations: Structure, Form, and Action: 25-57. Harvard Business School Press: Boston, MA.

Karney, B.R., \& Frye, N. E. 2002. "But we've been getting better lately": Comparing prospective and retrospective views of relationship development. Journal of Personality and Social Psychology, 82: 222-238.

Kilduff, M., Tsai, W., \& Hanke, R. 2006. A paradigm too far? A dynamic stability reconsideration of the social network research program. Academy of Management Review, 31: $1031-48$.

Kilduff, M. \& Krackhardt, D. 2008. Interpersonal networks in organizations: cognition, personality, dynamics, and culture. Cambridge University Press.

Kunin, T. 1955. The construction of a new type of attitude measure. Personnel Pscyhology, 8: $65-77$.

Krackhardt, D. 1987. Cognitive social structures. Social Networks, 9: 109-34.

Krackhardt, D. 1990. Assessing the political landscape: structure, cognition, and power in organizations. Administrative Science Quarterly, 35: 342-69.

Krackhardt, D., \& Kilduff, M. 1999. Whether close or far: social distance effects on perceived balance in friendship networks. Journal of Personality and Social Psychology, 76: 770-82. 
Mayhew, B. 1980. Structuralism versus individualism: I-shadowboxing in the dark. Social Forces, 59: 335-75.

McGrath, C., Blythe, J., \& Krackhard, D. 1997. The effect of spatial arrangement on judgments and errors in interpreting graphs. Social Networks, 19(3):223-242.

Mehra, A., Borgatti, S.P., Soltis, S., Kidwell, G., \& Floyd, T. 2010. Seeing networks in organizations: A novel approach to assessing the accuracy of network perceptions. Paper presented at the fourth ION conference, Lexington, KY.

Moreno, J.L. 1953. Who shall survive? Beacon: New York.

Nadel, S.F. 1958. The theory of social structure, The Free Press of Glencoe.

Neisser, U. 1976. Cognition and reality: principles and implications of cognitive psychology. Freeman: New York.

Podolny, J.M. 2003. A picture is worth a thousand symbols: a sociologist's view of the economic pursuit of truth. American Economic Association Papers and Proceedings: 169-174.

Sartre, J.P. 1936. L’imagination. Presses Universitaries de France.

Sasovova, Z., Mehra, A., Borgatti, S.P., Schippers, 2010. M. Network Churn: The Effects of Self-Monitoring Personality on Brokerage Dynamics. Administrative Science Quarterly 55(4): 639-670

Schutz, A. 1967. The phenomenology of the social world, George Walsh and Frederick Lehnert (trans.). Northwestern University Press: Evanston, IL. 
Schutz, A. 1978. The theory of social action: The correspondence of Alfred Schutz and Talcott Parsons, Richard Grathoff (ed.), Indiana University Press: Bloomington, IN.

Soltis, S. \& Floyd, T. 2013. Network perceptions, contextual performance, and personorganization fit. Paper to be presented at the 2013 meeting of the Academy of Management.

The Economist Magazine. 2013. Infographics: winds of change, July $6^{\text {th }}$.

Turchi, P. 2004. Maps of the imagination. Trinity University Press: San Antonio, Texas.

Wellman, B. 1988. Structural analysis: From metaphor to substance. In B. Wellman and S.D. Berkowitz (eds.), Social structures: a network approach: 19-61. Cambridge University Press: New York. 


\section{Figure 1}

\section{Explaining Network Images}

Mehra et al., 2013 C

In this section of the questionnaire, we ask about your perceptions of the overall pattern of close friendships in [the organization]. As you are probably aware, we can represent the structure of close friendships in [the organization] as a network in which a small circle is used to represent a person, and a line between two circles indicates that those two people are close friends. Here is a made-up example to illustrate what we mean:

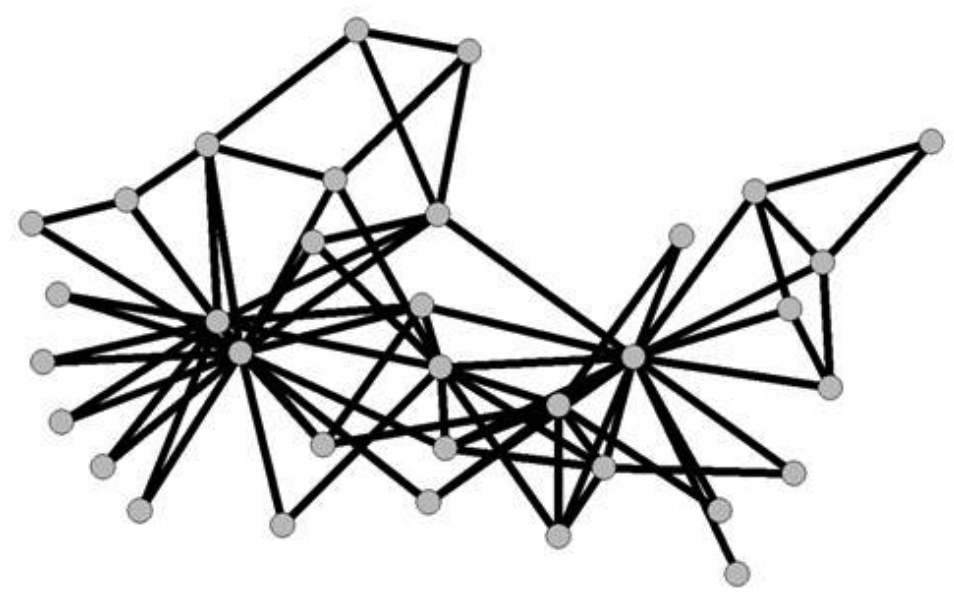




\section{Figure 2}

\section{Explaining Personal Network Images}

Mehra et al., 2013 (C)

In this section, we are going to show you some stylized pictures of your personal network of close friendships in [the organization]. By personal network we mean the set of relations among you, your close friends, and the relations among your close friends. In each diagram, the larger circle in the center is you; the other circles represent your close friends, and the lines between the circles represent close friendships. Please take a look at the pictures and their verbal descriptions, and then tell us which network YOU think looks most like your personal network of close friends in [the organization].

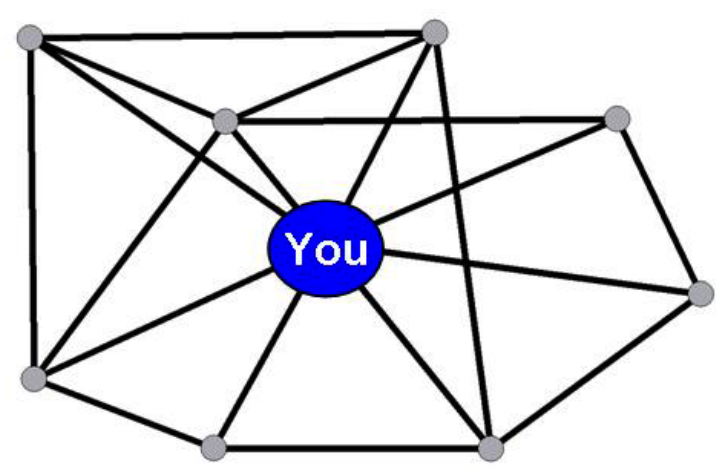




\section{Figure 3}

\section{Visual Scale to Capture Perception of Ego Network Density}

\section{Mehra et al., 2013 C}

This question focuses on your perceptions of the degree of interconnectedness among your close friends in [the organization].

In your opinion, which of the network diagrams below best approximates the degree of interconnectedness in your personal network of close friendships in [the organization]? Please make your selection by clicking one of the pictures below. Please select one choice.

1. None of my friends are

friends with each other

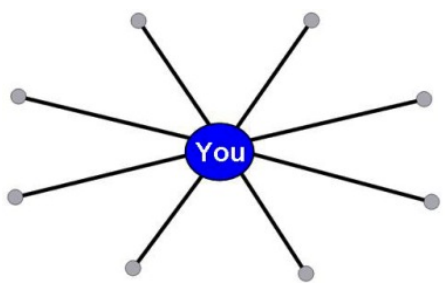

2. A few of my friends are friends with each other

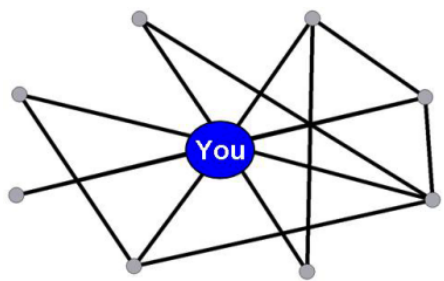

3. About half of my friends are friends with each other

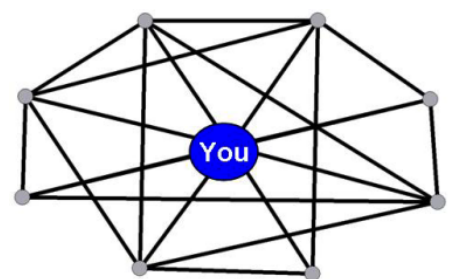

4. Most of my friends are friends with each other

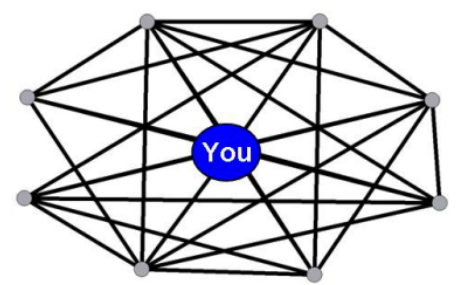

5. All of my friends are friends with each other

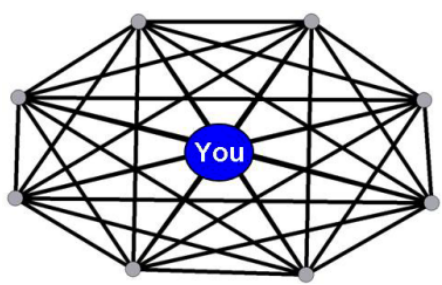




\section{Figure 4}

\section{Visual Scale to Capture Perception of Ego Network Bridging}

Mehra et al., 2013 (C)

In the diagram below, there are two groups/cliques of people. The large circle that connects the two groups/cliques can be thought of as a bridge.

Using the scale below, please rate the extent to which you think you occupy a bridging position in your personal network of close friendships in [the organization]-- i.e., the extent to which, like the "you circle," you are close friends with groups that otherwise lack close friendship relations with each other.

1: I do not occupy any bridging positions

$\bigcirc 2$

3

$\bigcirc 4$

5: I occupy many bridging positions

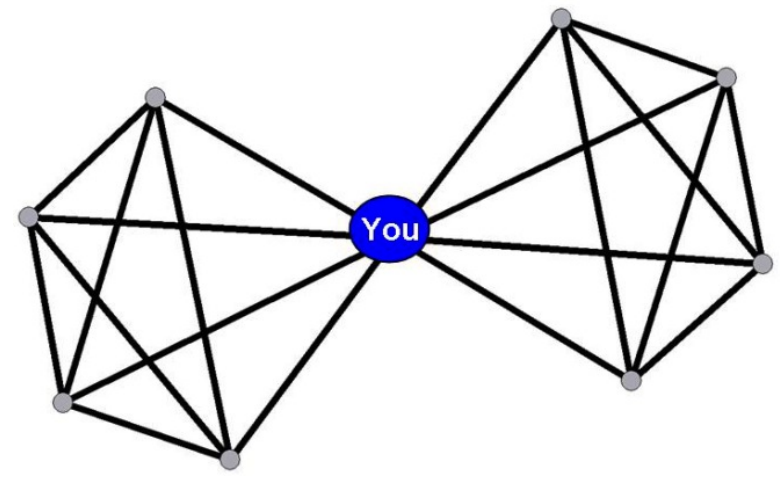




\section{Figure 5}

\section{Visual Scale to Capture Perception of Ego Network Reach}

Mehra et al., 2013 CC

Some of your close friends may have few other close friends (pictured on the left) while other of your close friends might have many close friends (pictured on the right).

In your opinion, which of the network diagrams below best approximates your personal network of close friendships in [the organization]? Please make your selection by clicking one of the pictures below. Please select one choice.

1. My friends have few close friends

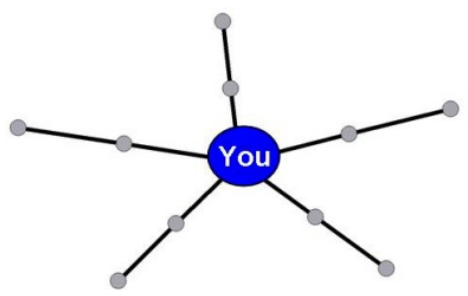

2. My friends have some close friends

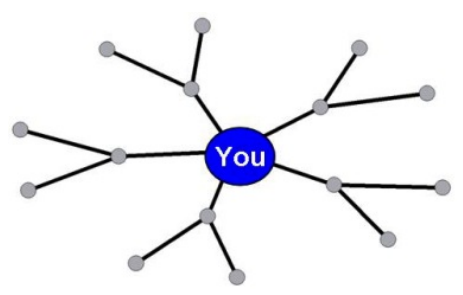

3. My friends have many close friends

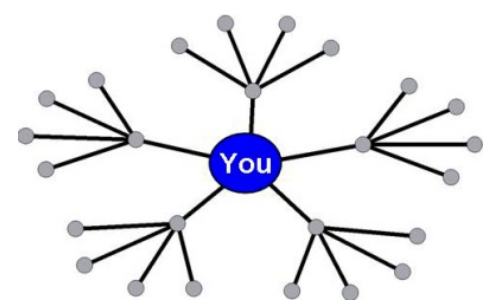




\section{Figure 6}

\section{Visual Scale to Capture Perception of Whole Network Density}

Mehra et al., 2013 CC

This question focuses on your perceptions of the degree of interconnectedness of close friendships within [the organization]. The more interconnected the network, the more dense the pattern of relations within the network is.

In your opinion, which of the network diagrams below best approximates the density of the network of close friendships in [the organization] as a whole. Please make your selection by clicking one of the pictures below. Please select one choice.

1: Very low network density
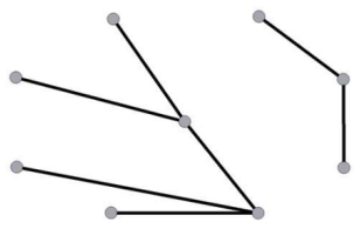

2: Low network density

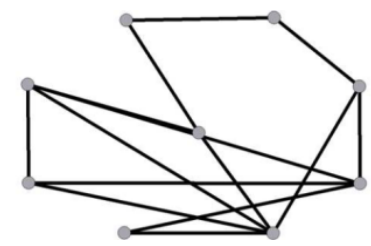

3: Moderate network density

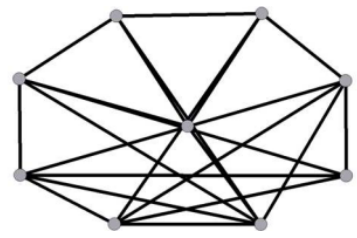

4: Relatively high network density

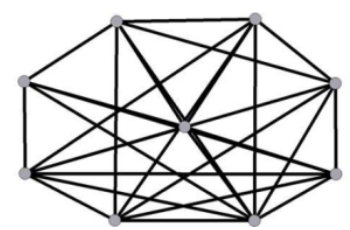

5: Very high network density

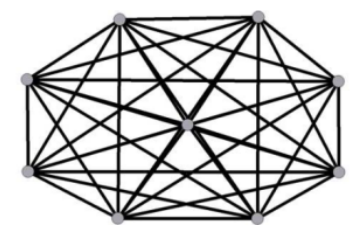


Figure 7

\section{Visual Scale to Capture Perceived Structure of Whole Network}

Mehra et al., 2013 (C)

In this part of the questionnaire, you will be asked to indicate how you see the overall network structure among all student participants of the SNA course.

There are four diagrams below.

(A) Core-periphery: in this network, there is a core of well-connected people, and most people are on the poorly connected margins of the network.

(B) Clique structure: this is a network composed of distinct cliques; members of a clique have lots of ties to each other and very few ties to people outside their own clique.

(C) Sparse network: this is a sparsely connected network; members have ties to only a few of the many people in the network.

(D) Dense network: this is a densely connected network; people have many ties to each other.

Please rank the four diagrams representing the overall structure of the friendship network by using numbers $1,2,3$, and 4 (meaning: 1 = most likely to $4=$ most unlikely).
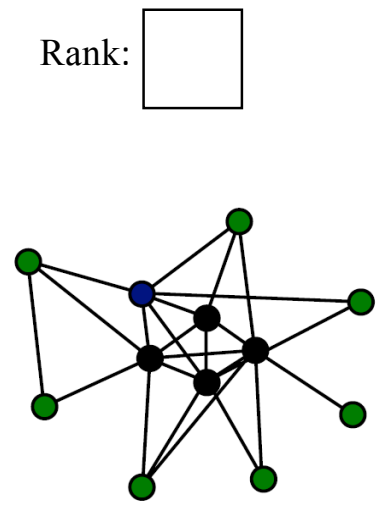

(A) core-periphery
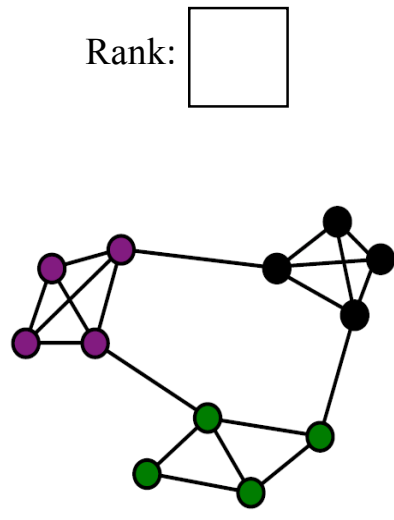

(B) clique structure
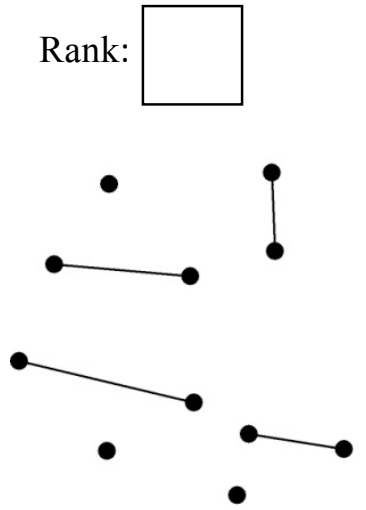

(C) sparse network
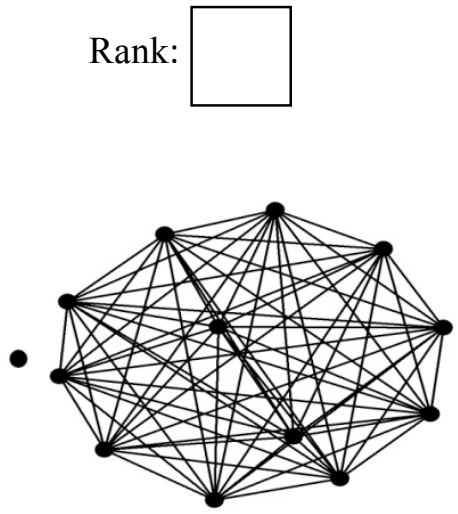

(D) dense network 


\section{Figure 8}

\section{Visual Scale to Capture Perceived Changes in Density}

Mehra et al., 2013 @

In this section, we ask you for your perceptions of the changes in your network of close friends in [the organization].

This question focuses on your perceptions of CHANGES in the degree of interconnectedness among your close friends in [the organization].

The network diagram on the left represents a personal network with NO interconnectedness. The network diagram on the right represents a personal network that is completely interconnected.
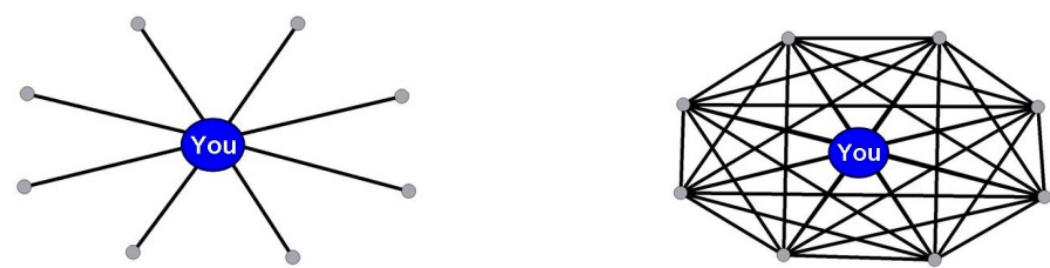

Using the scale below, please choose the answer that best represents your perception of how your network has changed since last year at this time.

\begin{tabular}{|c|cc|}
\hline $\begin{array}{c}\text { 1. My network has } \\
\text { become much less } \\
\text { connected. There are } \\
\begin{array}{c}\text { far fewer } \\
\text { interconnections than } \\
\text { last year. }\end{array}\end{array}$ & $\begin{array}{c}\text { 3. My network has } \\
\text { remained about the } \\
\text { same. The number of } \\
\text { interconnections is } \\
\text { very similar to last } \\
\text { year. }\end{array}$ & $\begin{array}{c}\text { 5. My network has } \\
\text { become much more } \\
\text { connected. There are } \\
\text { far more }\end{array}$ \\
\hline
\end{tabular}


Figure 9

Visual Scale to Capture Perception Changes in Bridging in the Personal Network

Mehra et al., 2013 C

This question focuses on your perceptions of the CHANGE in the number of bridging positions you occupy among your close friends in [the organization].

In the diagram below, there are two groups/cliques of people. The large circle that connects the two groups/cliques can be thought of as a bridge.

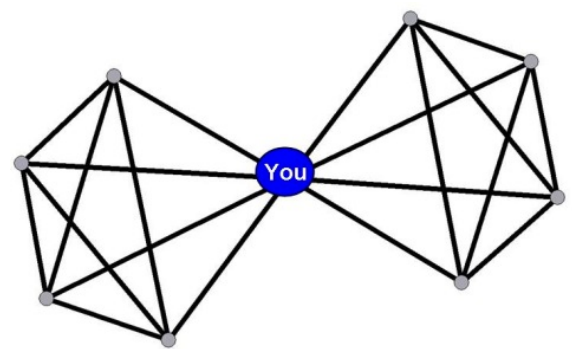

Using the scale below, please choose the answer that best represents how the number of bridging positions you occupy among your close friends in [the organization] has changed since last year at this time.

1. I occupy far fewer bridging positions among my close friends in [the organization].
3. The number of bridging positions I occupy has remained about the same.
5. I occupy many more bridging positions among my close friends in [the organization].

2

$\square$


Figure 10

\section{Visual Scale to Capture Perception of Change in Network Position}

Mehra et al., 2013 C

This question focuses on your perceptions of CHANGES in your position in the network of close friends in [the organization].

The network diagram on the left represents a person on the periphery of the network. This person has close friends who themselves are not connected to many others. The network diagram on the right represents a person in the center of the network. This person has close friends who themselves are connected to many others.
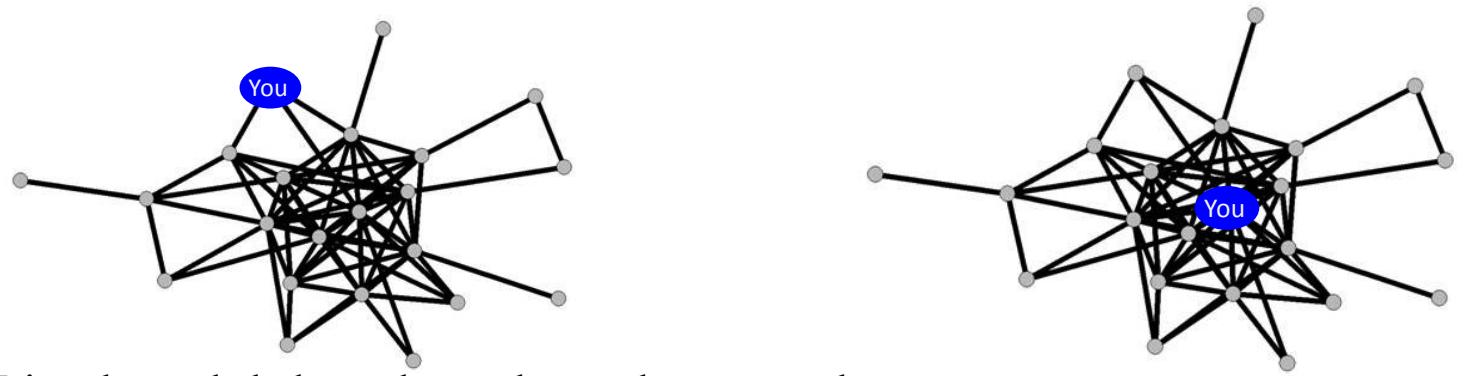

Using the scale below, please choose the answer that best represents your perception of how your position in the organization's network has changed since last year at this time.

\begin{tabular}{|c|c|c|}
\hline $\begin{array}{c}\text { 1. I have moved } \\
\text { more towards the } \\
\text { periphery of the } \\
\text { network. }\end{array}$ & $\begin{array}{c}\text { 3. My position in the } \\
\text { network has } \\
\text { remained about the } \\
\text { same. }\end{array}$ & $\begin{array}{c}\text { 5. I have moved } \\
\text { more towards the } \\
\text { center of the } \\
\text { network. }\end{array}$ \\
\hline$\square$
\end{tabular}




\section{Figure 11}

\section{Visual Scale to Capture Retrospective Perceptions of Friendship Tie Trajectories}

Mehra et al., 2013 @

Consider your relationships with your close friends. The way that each relationship progressed over time may be different from the others. You may have shared an instant bond with some friends, while for others, the friendship developed slowly over time.

The images below represent different ways that relationships may progress over time. The horizontal axis represents the passage of time. The vertical axis represents the status of the relationship and ranges from Strong Like at the top to Strong Dislike on the bottom.

Please enter FIVE of your close friends and select the image that best depicts the way that your friendship with each person has progressed over time.
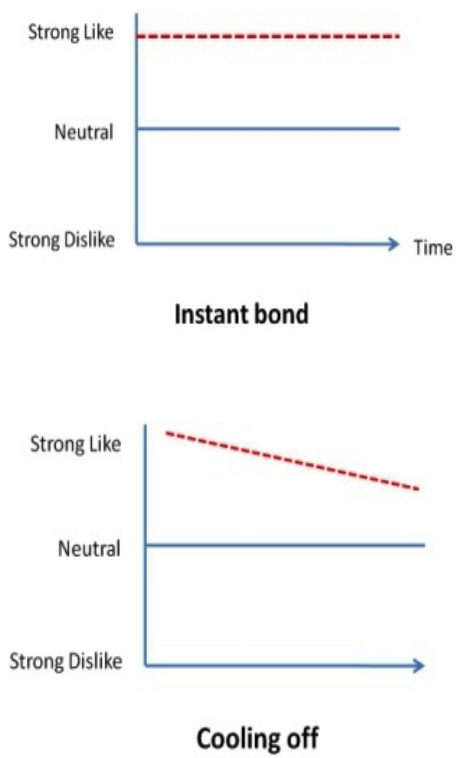
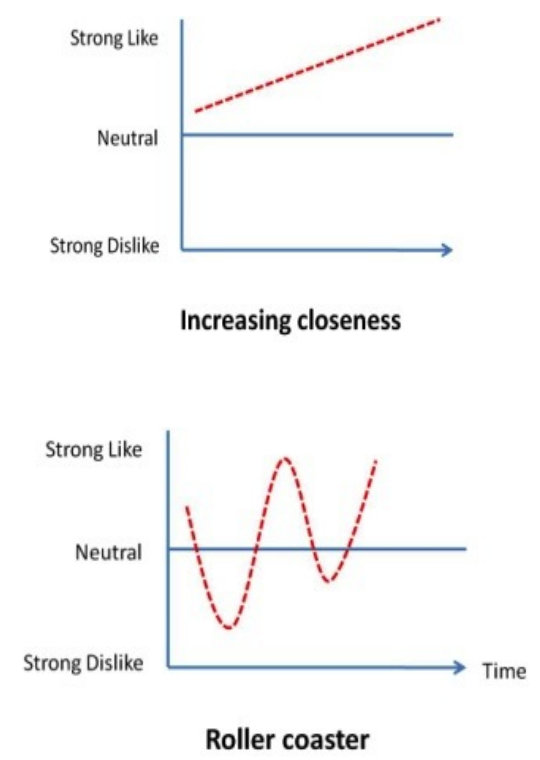
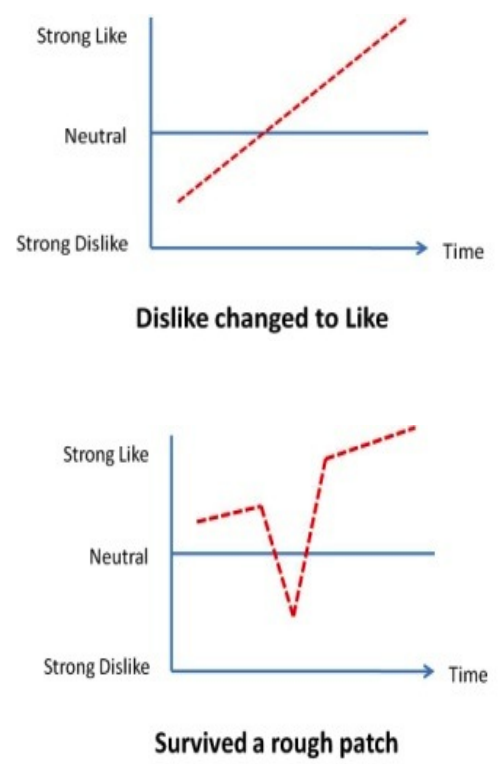


\section{Figure 12}

\section{Visual Scale to Capture Prospective Perceptions of Friendship Tie Trajectories \\ Mehra et al., 2013 @}

As you approach your graduation from [the university], there is a possibility that you will move away from your close friends. Imagine that after graduation, you move more than 100 miles away from each of the close friends listed below.

Then, for each friend you named, please select the image that best depicts the way you expect the friendship will progress or change AFTER the move.
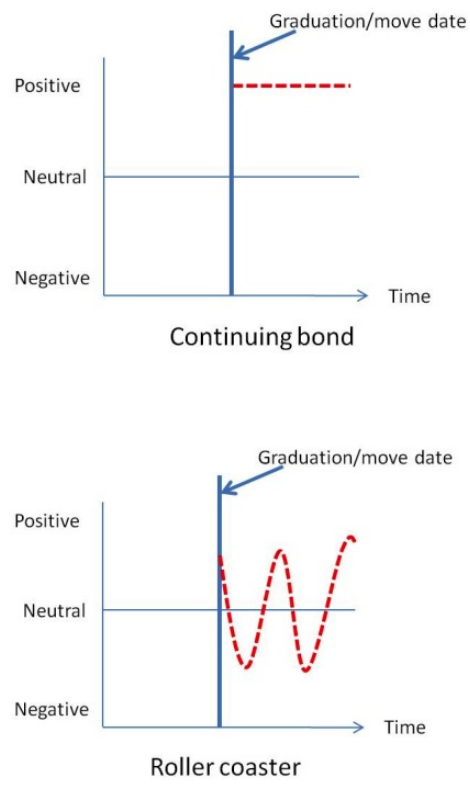
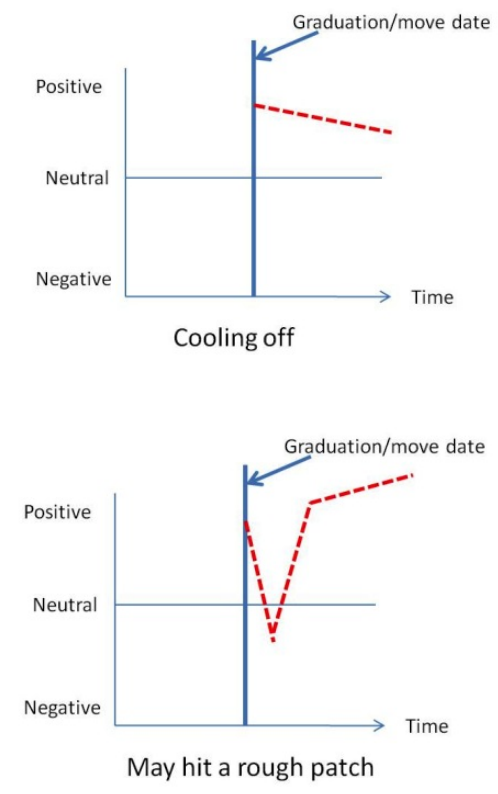
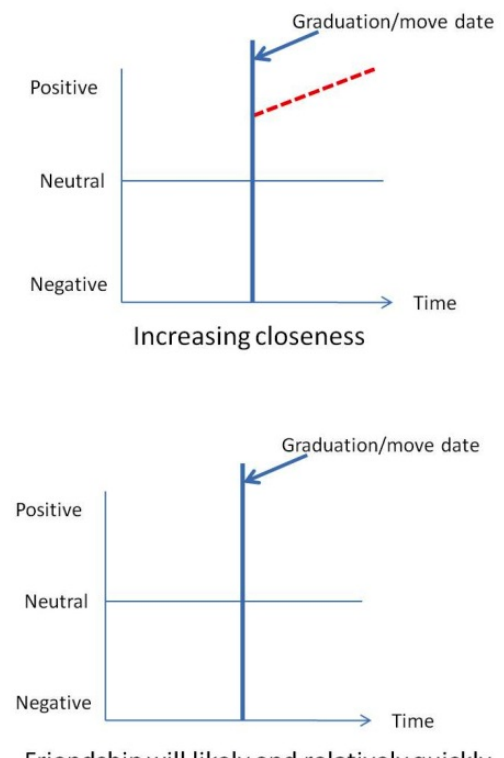

Friendship will likely end relatively quickly 


\section{Figure 13}

\section{Visual Scale to Capture Preference for Dense Networks}

Mehra et al., 2013 C

This question focuses on the degree of interconnectedness between a person and his or her close friends.

If this were your network, which diagram represents the degree of interconnectedness that you would prefer?
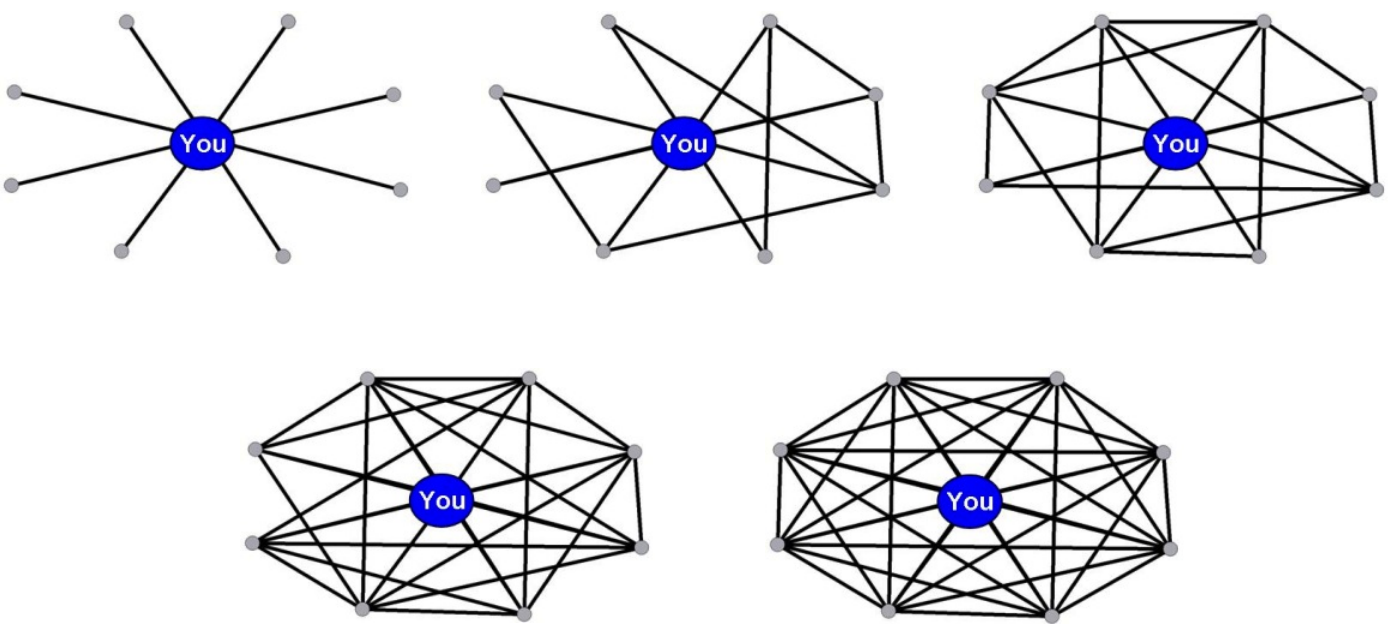


\section{Figure 14}

\section{Visual Scale to Capture Preference for Bridging Positions}

Mehra et al., 2013 C

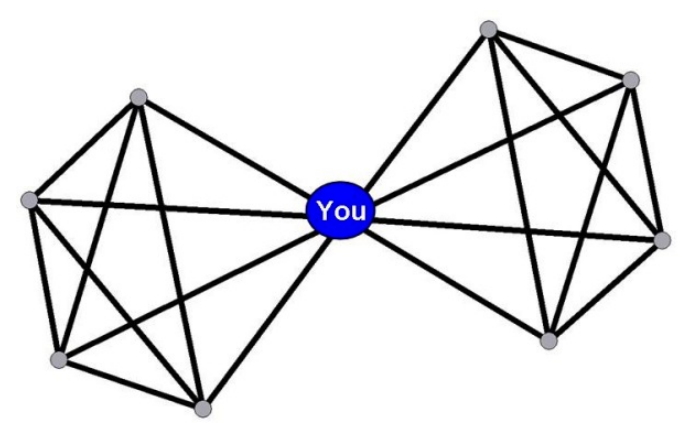

Using the scale below, please rate the extent to which you would prefer to occupy gobetween positions in your personal networks. i.e., the extent to which, like the "you circle," you would prefer to have close friendships with people in groups that otherwise lack close friendship relations with each other.

\author{
1 - I would \\ prefer not to \\ occupy any go- \\ between \\ positions \\ 0
}

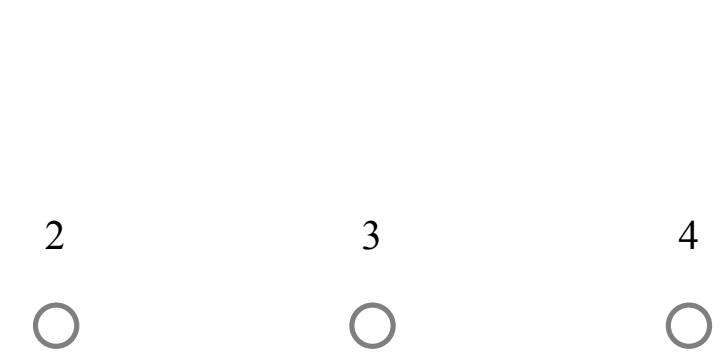

5 - I would prefer to occupy many gobetween positions 


\section{Figure 15}

\section{Visual Scale to Capture Preference for Network Reach}

Mehra et al., 2013 C

This question focuses on the extent to which a person's close friends have many other close friends, or how well-connected the principal person's close friends are.

If this were your network, which diagram represents how connected you would prefer your close friends to be?
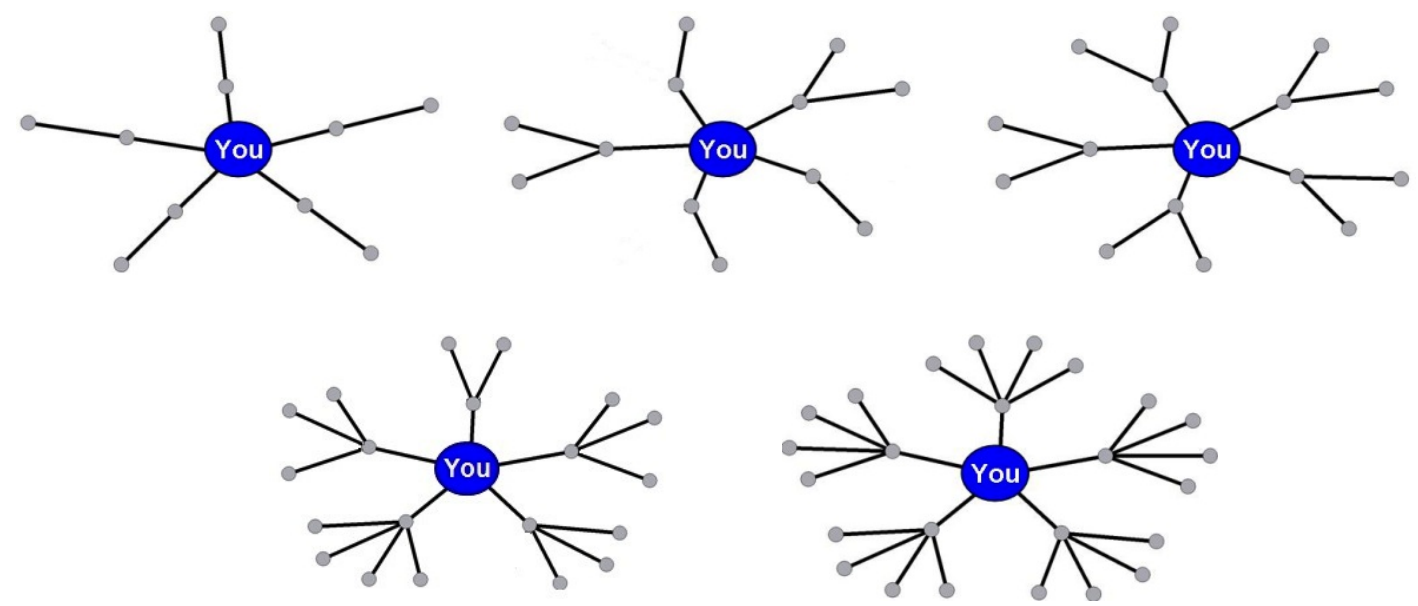
Figure 16

\section{Visual Scale to Capture Approach to Transforming Networks}

Mehra et al., 2013 C

People might occupy go-between positions for many different reasons. Sometimes, a person acts as a go-between for two other people simply because the two others do not know each other. Sometimes, a person acts as a go-between for two other people because the two others actively dislike each other.

The below image represents a person acting as a go-between for two others who do not know each other. Please think of times when you found yourself in this position.

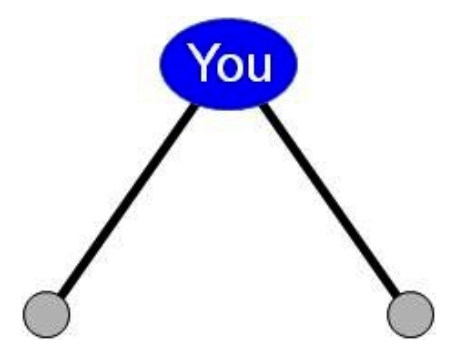

When you found yourself in this position, what has been your typical reaction?

I did not attempt to change things

I tried to arrange for the two people to meet

I dropped one of the two people as a friend 